\title{
The Impact of Anchor Borrower Programme on Poverty Alleviation in Argungu Local Government Area of Kebbi State
}

\author{
Badejo Bolaji Tinuke (Ph.D) \\ Department of Local Government Studies \\ Obafemi Awolowo University \\ Ile- Ife, Nigeria \\ $\&$ \\ Adekeye Adeshola Joseph (Ph.D) \\ Department of Public Administration \\ University of Abuja, FCT, Abuja, Nigeria
}

Received: Oct. 6, 2018 Accepted: Nov. 20, 2018 Online published: Dec. 11, 2018

doi:10.5296/jpag.v8i4.14049 URL: https://doi.org/10.5296/jpag.v8i4.14049

\begin{abstract}
This research work was designed to examine the impact of Anchor Borrower Programme (ABP) on poverty alleviation in Argungu Local Government Area of Kebbi State. The main objective of the study is to investigate the extent to which the implementation of Anchor Borrower Programme (ABP) has encouraged poverty alleviation in the area of food supply, income generation, improvement in standard of living and income generation in the study area. Relevant data for this research work were collected from secondary sources through the content analysis of; documents, government publications, reports, quarterly magazines on Anchor Borrower Programme and data from Bureau of Statistics. At the end of the study, the research findings reveal that Anchor Borrower Programmes (ABP) supports for farmer have a positive and significant impact on poverty alleviation in the area of; food supply, employment generation, improved standard of living and income generation was substantial. However, the paper recommended that the Anchor Borrower policy in Nigeria should be encouraged and subjected to periodic review so as to provide more platforms for poverty alleviation in Argungu LGA of Kebbi State.
\end{abstract}

Keywords: public policy, agriculture, modernization theory, policy implementation 


\section{Introduction}

Agriculture was the main stay of Nigeria economy before the discovery of Oil in 1958. As a matter of fact, Nigeria was exporting agricultural produce such as; groundnut, cocoa, rubber, cotton, groundnut oil, cassava and yam to other part of the world. Agriculture was the Nigeria's major sources of foreign exchange earnings before the attainment of independence in 1960. Subsequently, the discovery of oil in commercial quantity made Nigeria to abandon agriculture. Although, laudable efforts were made by successive governments in the introduction of programmes such as; Green Revolution, Operation Feed the Nation and Agricultural Development Programme (ADP), etc. but it appear that the political will to pursue such programmes to logical conclusion was lacking. This is so because; no effort was made towards the reduction in interest rates for farm loan or reduction in tariff for agricultural inputs. By implication, the larger proportion of farmers in Nigeria since independence usually engage in subsistence farming which focuses on the production of food for their families with little or nothing left over for sale.

In light of the above, the Nigeria Agricultural Cooperative Bank which later metamorphosed into Nigerian Agricultural Cooperative and Rural Development Bank was established with the mandate of making agricultural credits available to farmers at lower interest rates. However, the farmers who are supposed to benefit from the above scheme were side-lined through the activities of middlemen who are out to make profit at the expense of genuine farmers. In efforts towards reversing the above ugly trends, the Buhari Administration decided to take the bull by the horn in introducing the Anchor Borrower Scheme for farmers in Nigeria. This programme encourages the lending of agricultural credits to farmers at $9 \%$ interest rates by the Central Bank of Nigeria. Most State governments who decided to key themselves into the Anchor Borrower Scheme are now producing local rice, fish, maize, guinea corn, melon and cocoa in large quantity for same. In the case of Argungu Local Government Area of Kebbi State, a lot of giant stride has been made. In light of the above, this paper seeks to examine the impact of Anchor Borrower Scheme on poverty Alleviation in Argungu Local Government Area of Kebbi State.

\section{Conceptual Framework}

It is imperative to conceptualize some terms considered fundamental to this study in for readers to be acquainted with the subject matter of the paper. Therefore, the views of notable scholars on the following concepts are presented below:

\section{a) Public Policy}

By policy, we mean a "set of decisions taken by a political actor or group concerning the selection of goals and the method of attaining them, relating to a specified situation" (Roberts and Edwards, 1991:98). Defining policy in this context corroborates with the view that, "it is a fiction rather than the actual realization of how policy is created, but has been influential on how people look at policy in general" (Robert, 1987).

A policy option made by an individual is known as "private policy" because it affects the person alone and no any other person. Barret and Fudge (1981:5) argued that we talk of 
"public policy" when a policy:

Emanates from the 'public sector' including both the institutions and central and local government and state created agencies such as water or health authorities, commissions and corporations - it may be implemented through and directed at a wide variety of individuals and organizations may or may not be part of the State apparatus, and which may be greater or in lesser degree independent.

Going by the above assertion, it implies that policy takes critical consideration of factor(s) affecting a particular "target population" in a geo-politically defined territory. Public policy however, acknowledges the fact that "planning" forms the bedrock of public policy. Planning is explained by Chandler and Plano (1998:92) as:

Conceiving meaningful goals and developing alternative choices for the future action to achieve these goals. Planning involves a systematic procedure for the reduction of many alternatives to an approved course of action. It determines not only goals but the sequential order in which they are pursued for maintaining control.

In essence, policy analysis or public policy analysis may be used as a term to describe the detail examination of a particular public policy system at any and/or all the stages of policy making process. The processes are policy identification (need), policy studies, policy demands, policy decisions, policy outputs and policy outcomes (Olaniyi, 2001:19-20). The unrealistic nature of effective policy actualization at the local government in Nigeria is not unconnected to Theodore Lowi (1964) argument, who identified the distributive, redistributive and regulatory policies being purposes or types of policy, of which analysis could be based on the number of purposes or types of policy, could be based on the number of people affected by a policy and their relationships with another, on one hand, and the expected outputs on the other hand. Pertinent to this article is to clearly define these terms 'public policy formulation' and 'public policy implementation.

To conceptualize policy formulation and implementation presupposes an examination of public policy because the two in one concept is subsumed under public policy analysis. Public policy issue is a subset or particular realm in politics, while its analysis is a subdivision of politics, a field affiliated to Political Science. An exemplification of public policy is argued by Snyder (1996), "that the formulation and execution of public policy is one of the major areas of future growth in Political Science," and by extension, local government.

Public policy formulation is referred as that part of the process by which proposed actions are articulated, debated, and drafted into language for law or policy (The Policy Circle, 2013). Public policy implementation can be to as the carrying out of basic policy decision, usually incorporated in a statute, but which can also take the form of important executive orders or court decisions (Mazmanian and Sabatier, 1983). The unrealistic nature of effective policy actualization at the local government in Nigeria is not unconnected to Theodore Lowi's (1964) argument, who identified the distributive, redistributive and regulatory policies being 
purposes or types of policy, of which analysis could be based on the number of purposes or types of policy, could be based on the number of people affected by a policy and their relationships with another, on one hand, and the expected outputs on the other hand

\section{b) Agriculture}

Agriculture involves the preparation of land for the purposes of food and animal production. According to Mabuza, Taeb and Endo (2008), agriculture is the cultivation of land, raising and rearing of animals for the purpose of production of food for man, animals and industries. It involves and comprises of crop production, livestock and forestry, fishery, processing and marketing of those agricultural production. Successive governments in Nigeria since independent have formulated a number of programmes and strategies aimed at encouraging the growth and development of agriculture. These measures included the setting up of large-scale mechanized farms by state and federal government, introduction of scheme such as the River Basin Development Authority. Other measures include, National Accelerated Food Production (NAFP), Operation Feed the Nation (OFN), Green Revolution (GRP) and the Directorate for Food, Roads and Rural Infrastructure (Uniamikogbo and Enoma, 2001)

\section{Theoretical Framework}

Modernization theory is used to explain the process of modernization within societies. Modernization refers to a model of a progressive transition from a 'pre-modern' or 'traditional' to a 'modern' society. Modernization theory originated from the ideas of German sociologist Max Weber (1864-1920), which provided the basis for the modernization paradigm developed by Harvard sociologist Talcott Parsons (1902-1979). The theory looks at the internal factors of a country while assuming that with assistance, "traditional" countries can be brought to development in the same manner more developed countries have been. Modernization theory was a dominant paradigm in the social sciences in the 1950s and 1960s, then went into a deep eclipse. It made a comeback after 1990 but remains a controversial model (Knobl, 2003).

Modernization theory both attempts to identify the social variables that contribute to social progress and development of societies and seeks to explain the process of social evolution. Modernization theory is subject to criticism originating among socialist and free-market theorists, globalization theorists and dependency theorists among others. Modernization theory stresses not only the process of change but also the responses to that change. It also looks at internal dynamics while referring to social and cultural structures and the adaptation of new technologies. Modernization theory maintains that traditional societies will develop as they adopt more modern practices. Proponents of modernization theory claim that modern states are wealthier and more powerful and that their citizens are freer to enjoy a higher standard of living. Developments such as new data technology and the need to update traditional methods in transport, communication and production, it is argued, make modernization necessary or at least preferable to the status quo. That view makes critique of modernization difficult since it implies that such developments control the limits of human interaction, not vice versa. It also implies that human agency controls the speed and severity of modernization. Supposedly, instead of being dominated by tradition, societies undergoing 
the process of modernization typically arrive at forms of governance dictated by abstract principles. Traditional religious beliefs and cultural traits, according to the theory, usually become less important as modernization takes hold (Henry, 1971).

From the 1960s, modernization theory has been criticized by numerous scholars, including Andre Gunder Frank (1929-2005) and Immanuel Wallerstein (born 1930). In this model, the modernization of a society required the destruction of the indigenous culture and its replacement by a more Westernized one. By one definition, modern simply refers to the present, and any society still in existence is therefore modern. Proponents of modernization typically view only Western society as being truly modern and argue that others are primitive or un-evolved by comparison. That view sees un-modernized societies as inferior even if they have the same standard of living as western societies. Opponents argue that modernity is independent of culture and can be adapted to any society. Japan is cited as an example by both sides. Some see it as proof that a thoroughly modern way of life can exist in a non western society. Others argue that Japan has become distinctly more western as a result of its modernization. The theory has also been criticised empirically, as modernization theorists ignore external sources of change in societies. The binary between traditional and modern is unhelpful, as the two are linked and often interdependent, and 'modernization' does not come as a whole (Tipps, 1973).

Modernization theory has also been accused of being Eurocentric, as modernization began in Europe, with the Industrial Revolution, the French Revolution and the Revolutions of 1848 (Macionis, 1953) and has long been regarded as reaching its most advanced stage in Europe. Anthropologists typically make their criticism one step further and say that the view is ethnocentric and is specific to Western culture. Despites the above criticism against the modernization theory, it is applicable to this paper since its major postulations encourages the introduction of modernized agriculture through provision of credits for farmers at lower interest rates.

Sequel to the introduction of Anchor Borrower Scheme, farmers finds it difficult if not impossible to secure agricultural credit for farming activities. Many who even wanted to go into the practice grow cold minds when they discovered that without credit, there will be low agricultural output. The modernization of agriculture can only become feasible in Nigeria when farms have access to adequate credit facilities. With the introduction of machines into agriculture, Nigeria will see agriculture as something interesting and start engaging in it. Advancing agriculture, like the new and improved system of farming and poultry will propel many to venture into it and thus pick such as means of meeting their basic needs.

\section{Anchor Borrower Programme Implementation Strategy}

The ABP implementation approach is hinged on three pronged support; comprising the out-grower scheme, which will direct support to the participating farmers, covering issues on farmer and group identification, cluster groupings, linkage to off-takers, farmer registration and Bank Verification Number (BVN) with Bank of Industry and other financial institutions, signing of Memorandum of Understanding (MoU), credit support (kind and financial), monitoring, etc. The second component consist of capacity building of stakeholders, 
including the extension agents, agro-input service providers, financial institutions, anchor companies and the farmers. The risk mitigation component covers, but is not be limited to issues arising from poor farming techniques, unskilled credit officers, weak management, challenges on the part of farmers, poor quality agro-inputs, market challenges, price volatility, loss of harvests, diversion of output, etc.

\section{Stages of Programme Implementation/Transaction Dynamics}

The stages of $\mathrm{ABP}$ implementation consists of the following:

I. Sourcing of funds from the N220 billion Medium, Small and Micro Enterprise Development Fund to be disbursed to farmers at $9 \%$ interest rate, with crop specific tenors;

II. Identification and verification of targeted beneficiaries (farmers with 1-3 hectares varied cultivable land);

III. Grouping of farmers into cooperatives linked to anchor companies;

IV. Training of farmers and certification;

V. Opening of bank accounts by farmers, with banks and receipt of Bank Verification Number;

VI. Town hall meeting to discuss with stakeholders (Anchor, Participating Financial Institutions, farmers, CBN, Agricultural Development Programmes (ADPs), input suppliers, Nigerian Agricultural Insurance Corporation (NAIC), etc;

VII. Reaching agreement on key implementation modalities (economics of production, input supply, agreed baseline price, disbursement modalities, payment terms, cross gurantee by farmers and default consequences);

VIII. Disbursement to beneficiaries in kind and cash through banks; and

IX. Strategic monitoring and direction of programme (Figure 3) (Source: CBN, 2016).

\section{Programme Stakeholders and Their Roles}

The programme stakeholders are to work closely with financial institutions, including insurance companies, Nigeria Incentive-based Risk Sharing for Agricultural Lending (NIRSAL) and the CBN, to create the linkages and transparency required to sustainably enhance the production of the identified commodities. The key stakeholders include the CBN, NIRSAL, FMARD, NAIC, Bank of Agriculture (BOA), state governments/ADPs; anchor companies; financing banks; insurance companies; development partners; farmers/out-growers and programme management team.

\section{Issues Arising from ABP Implementation}

A general review of the ABP implementation stages threw up numerous issues, particularly at the loan disbursement stage. According to the National Treasurer of the Rice Farmers Association of Nigeria (RIFAN), Sadiq Daware (World Stage, 2018), many farmers 
complained of not being able to access loan while others were not given the right amount proposed under the programme. He further noted that even though CBN disbursed N43.92 billion to farmers through 13 participating institutions, some of these institutions frustrated the efforts of the farmers in accessing the facility while some were not farmer friendly due to complicated transaction procedures and non-consideration of gestation periods of crop growing. Some Banks further insisted that $\mathrm{CBN}$ was yet to give specific guidelines on how to disburse the loans. In a related development, agro-input distribution was observed to be haphazard. Some farmers were given fertilizers while others were denied.

Some of the criteria for participation under the programme may likely exclude the core poor and vulnerable groups including the women, given their inability to meet up with the farm holding requirement of between 1 and 5 hectares, as a result of their being disadvantaged in asset ownerships. Several institutions and researchers (World Bank 2012; African Development Bank (AfDB) 2014; Coker et al. 2016) have all affirmed the female gender's low access to land acquisition and holdings compared to their male counterpart. Participation in the programme requires stages of farmer registration, which is not without its cost. Aside this, linkage to the Growth Enhancement Support data base under the Agricultural Transformation Agenda (ATA), may have been partial, given that fresh farmer registration were being contemplated in some states. Initiating a fresh database amounts to colossal waste of public resources and thus confirms the existence of government inconsistency in the agriculture sector. Also, going by the interaction with some stakeholders, focus seems to have been more on funds disbursement and recovery, with little attention on the revolving nature of loan after recovery. According to the Chief Executive of the BOA, Professor Danbala Danju, commercial banks opted out of the programme, because it was not considered profitable (Guardian Newspaper, 2016). Without preconception to the risk component of the programme, basing sustainability on sustained credit source and market may not be proper, sufficient, without sound financial and economic analysis.

Expectations are that proper financial and economic analysis of the programme should have been undertaken at the commencement of the programme, rather than letting political consideration becloud sound economic assessment. Gittinger (1984) established that the capacity to prepare and analyse projects lags in many developing countries. He averred that administrators, even those in important planning positions, continually underestimate the time and effort needed to prepare suitable projects and that so, much attention is paid to policy formulation and planning, that specific projects on which to spend available money and on which much development depends are overlooked. According to him, Ill-conceived, hastily planned projects, virtually improvised on the spot, are too often the result.

\section{The Kebbi State Experience of Anchor Borrower Programmes}

Kebbi state was created out of the former Sokoto State on 17 August 1991. The State has a total population of 3,137,989 people as projected from the 1991 census, within 21 Local Government areas. The state has Sudan and sahel-savannah. The southern part is generally rocky with the Niger River traversing the state from Benin to Ngaski LGA. The northern part of the state is sandy with the Rima River passing through Argungu to Bagudo LGA where it 
empties into the Niger. Agriculture is the main occupation of the people especially in rural areas, Crops produced are mainly grains; animal rearing and fishing are also common. Christianity and Islam are the dominant religions of the people. There are 225 political wards, 3000 settlements and 1036 hard to reach settlements in the 21 Local Government Areas in the State. Argungu is a city in Nigeria's Kebbi State, situated on the Sokoto River. As of 2007 Argungu had an estimated population of 47,064. The city is the seat of the Argungu Emirate, a traditional state. The city is a major agricultural center for the area, with key crops including tobacco, peanuts, rice, millet, and sorghum. The city also hosts an annual international fishing competition.

Abubakar Atiku Bagudu since assuming office in 2015, has transformed Kebbi State from being a purely civil servant state and made it more industrialised. Kebbi State has become one of the major producers of rice in Nigeria. The current participation of more than 70,000 farmers in the Anchor Borrowers Rice and wheat farming is heading towards making Kebbi a new destination and hub for agro based commodities of the Country. Abubakar Bagudu then led a high level delegation from Kebbi to visit Lagos state in a bid to encourage inter-state relations in the Agric sector. Part of the deliberations include a number of mutual trade relations including Rice production and marketing alliance, Animals trade, farm produce processing and marketing as well as tourism promotions. At the end of deliberations, A Memorandum of Understanding was signed, which they aid would culminate in the production of $70 \%$ of Nigeria's rice requirements annually.

In addition, Officials of the Flour Mills of Nigeria Plc led by its Managing Director were not left out of this quest of exploring the agriculture potentials of Kebbi State. The giant Flour Mills Plc aims to establish a full fledges Flour Mills Company in the State, because of the abundance rice cultivation and production which cut across 17 out of the 21 local government areas of the State. Abubakar Bagudu is also the Chairman, National Task Force on Rice and Wheat Production in Nigeria. There are three cropping seasons in Kebbi State: two dry seasons and one wet season. Farmers produce rice in the three cropping seasons. Both farmers in the ABP and outside it have about 400,000 hectares under cultivation, and for those under the $\mathrm{ABP}$, about five to six tonnes minimum per hectare are expected; there you have about 1.2 million tonnes. For the rest of the farmers not under the ABP, their yields are lower (bout three tonnes per hectare). So for those 200,000 hectares, it is another 600,000. For cropping seasons, there is about 1.8 to almost two million tonnes per cropping season

A total of 70,000 farmers were participating in Kebbi State, with arrangements made for off-takers to buy off the output of out-growers. National Youth Service Corps (NYSC) members were also recruited to assist in the documentation of the farmers and their farms. Equally, unemployed graduates were deployed for Train the Trainers (TOT) programme under the initiative, while 105 extension workers were mobilized to assist farmers with loan disbursement arrangement through the BOA.

\section{Challenges Confronting the Implementation of Anchor Borrower Programme}

The implementation of Anchor Borrower Programme is fraught with myriad of challenges despites the above success story In the first place, the programme rests largely on the 
assumption of continued ban on importation of foreign rice and operation of reasonable exchange rate regime. Unbanning rice or poor border enforcement and over valuing the exchange rates may diminish the gains of the programme, given the possibility of encouraging importation. Weak synergy of national programmes with development and donor projects and programmes and standardised point of entry has also been one of the key limitations to agricultural growth and development

Aside the concern raised above, Kebbi State deployed NYSC members for its Training the Trainers (ToT), with arrangements put in place in the other states but though not clear. There also seems to be variation in loan recovery mechanism too; while the BOA is proposing to use collection centres, BOI staff, security agencies, and traditional rulers to recover funds, some of the collaborating institutions are logically using the framework of the registered groups and financial institutions to recover funds disbursed. Reports from Kebbi State (allafrica.com) showed that close political associates of the political class may have been hijacking and displacing real farmers under the programme. In addition, some real farmers have also been unable to access targeted loans, three months into the programme, thus leading to abandonment in some quarters. There are also likely to be limited experience in capacity building, group dynamics, best production practices and business agriculture, thus leading to the use of inexperienced and make shift resource persons for the Train the Trainers in some states. There have also been cases of weak information on programme's implementation arrangements, particularly at the lower tiers of implementation. Inadequate understanding of the programme's implementation arrangements may lead to confusion and exclusion. Though, there are programme objectives and strategies guiding the implementation of the programme, there are doubts as to the availability of a comprehensive results framework guiding the implementation of the programme.

\section{Conclusion}

The outcome of this paper revealed that the implementation of Anchor Borrower Programme in Kabi State and Argungu in particular has contributed immensely in the area of; employment generation, food production, income generation and the provision of raw material to industries. Specifically, the programme recorded commendable achievements in its attempt at substituting rice import, empowerment of farmers through the provision of subsidized agro-inputs and starter pack and cash, farmer profiling, development of cooperative and banking culture. The wide scope of targeted value chains further enhanced participation by shades of smallholder farmers. In-spite of the perceived benefits of the programme, the paper discovered that some aspects of ABP implementation arrangements are still unclear due to limited awareness of programme implementation arrangements, roles of stakeholders are overlapping, updated database are still an issue, credible monitoring and evaluation framework are lacking, while cases of elite capture may be prevalent.

\section{Recommendations}

Arising from the outcome of this paper, the following recommendations are considered necessary for the sustainability of Anchor Borrower Programme in Kebbi State: 
1. There is need to further reduce the $9 \%$ interest been charged on loans being borrowed by farmers to $5 \%$ in order to encourage more participants to enroll in the programme. Also, the maturity period for loan re-payment should be within 5 years gestation period due to inconsistency in farm produce.

2. The farmers need to be equipped with up-to-date skills and knowledge of modern farming through regular capacity building by extension workers. This will go a long way in increasing the production capacity of local farmers.

3. There is need for proper sensitization and enlightenment of farmers in Kebbi State about the numerous benefits derivable in obtaining loans from Anchor Borrower Programme. This is necessary because, so many people are not even aware of the existence of the scheme in remote villages.

4. The loans should be disbursed directly to local farmers instead of allowing the middlemen, politicians, and elites to hijack the resources from the real beneficiaries.

5. There is need for proper monitoring of the programme in order to ensure that farmers are able to re-pay back all credit facilities with appropriate interests at the stipulated time. This will go a long way in encouraging the sustainability of the programme

\section{References}

African Development Bank (AfDB). (2014). AfDB Gender Strategy (2014-2018).

Barrest, S., \& Fudge, C. (1981). Examining the Policy-Action Relationship in Barett, S. and Fudge, C. (Eds.) Policy and Action: Essays on the Implementation of Public Policy, London and New York: Methuen.

Chandler R. C., \& Plano, J. C. (1998). The Public Administration Dictionary. England: ABC-CLIO.

Coker, A. A. A., Ahmed, A. A., Adebayo, C. O., \& Alabi, O. O. (2016). Enhancing States'Agricultural Development Programmes'Efficiency through Innovative Results-based and Performance Management System - A Case of Federal Capital Territory ADP.

Danju, N. (2016) On Domestic Sufficiency in rice, we are poised to deliver in two years. Kogi: 5000 Rice Farmers set for CBN's Anchor Borrower Programme. Guardian, Sunday 24th July, 2016.

Gittinger, J. P. (1984). Economic Analysis of Agricultural Projects. Economic Development Institute. The World Bank, Washington, United States of America

Henry, B. (1971). Modernization theory and the sociological study of development*." Journal of Development Studies, 7(2), 141-60. https://doi.org/10.1080/00220387108421356

Knobl, W. (2003). Theories That Won't Pass Away: The Never-ending Story." in Gerard Delanty, Engin F. Isin, eds. Handbook of Historical Sociology: 96-107 esp p. 97 online.

Mabuza, M. L., Taeb, M., \& Endo, M. (2008). Impact of food aid on small wolder. Agricultural 


\section{Macrothink}

Journal of Public Administration and Governance

development in Swaziland. African Journal of Agriculture, 8(2), 151-169.

Mazmanian, D., \& Sabatier, P. A. (1983). Implementation and Public Policy. Palo Alto: Scott, ForesmanOkolie, A. M. (2003). "Political Analysis”. Mimeograph for M.Sc. Lecture, UNN.

Olaniyi, J. O. (2001). Foundation of Public Policy Analysis. Ibadan: Sunad Publishers Ltd.

Robert, T. N. (1987). The Textbook on Policy Process and Implementation Research, in Review of Policy Research, 7(1), 42-154.

The Policy Circle (2013). The Process: Policy Development, U.S. Agency for International Development (USAID), June 2.

Tipps, D. C. (1973). Modernization theory and the comparative study of national societies: A critical perspective. Comparative Studies in Society and History, 15(2), 199-226. https://doi.org/10.1017/S0010417500007039

Uniamikogbo, S. O., \& Enoma, A. I. (2001). The Impact of monetary policy on manufacturing sector in Nigeria: an empirical analysis. The Nigerian Journal of Economic and Financial Review, 3(2), 37-45.

\section{Copyright Disclaimer}

Copyright for this article is retained by the author(s), with first publication rights granted to the journal.

This is an open-access article distributed under the terms and conditions of the Creative Commons Attribution license (http://creativecommons.org/licenses/by/4.0/). 